\title{
Perfil das internações por encefalite viral no Brasil em 2018 por unidade da federação, sexo e faixa etária
}

\author{
Profile of hospitalizations for viral encephalitis in Brazil in 2018 per state, sex, \\ and age group
}

Elena Caires Silveira ${ }^{1}$ (D)

\begin{abstract}
RESUMO
Introdução: A encefalite viral é uma condição com altas taxas de morbimortalidade, e um melhor entendimento de sua epidemiologia pode colaborar para a construção de estratégias de prevenção e controle. Diante disso, este estudo se propôs a traçar um perfil epidemiológico para a encefalite viral no Brasil no ano de 2018 a partir de dados de internações hospitalares no Sistema Único de Saúde (SUS). Métodos: Estudo ecológico de análise espacial. Os dados estudados foram relativos às internações hospitalares por encefalite viral no SUS em 2018, estratificadas por unidade da federação (UF), sexo e faixa etária. A distribuição geográfica foi abordada exploratoriamente, já as variáveis sexo e faixa etária foram abordadas analiticamente. Resultados: Foram registradas 2075 internações, com taxa de $0,99 / 10^{5}$ habitantes. As taxas para cada UF foram representadas a partir de um mapa colorimétrico, enquanto as taxas para cada sexo e faixa etária foram representadas em uma tabela comparativa univariada. Discussão: Observou-se ampla variação numérica das taxas de internação dentre as UF, sendo Pernambuco o estado com maior incidência $\left(4,13 / 10^{5}\right.$ habitantes) e Paraíba o estado com menor $\left(0,29 / 10^{5}\right.$ habitantes). Foi constatada associação significativa com o risco de internação hospitalar por encefalite viral para o sexo masculino e para as faixas etárias de 1 a 4 anos (RR: 3,28) e menores de 1 ano (RR: 6,02). Conclusão: UF, gênero e faixa etária foram determinantes importantes da taxa de internação hospitalar por encefalite viral. Todavia, carecem de estudos atuais no Brasil e no mundo para a melhor caracterização da epidemiologia da encefalite viral.
\end{abstract}

Palavras-chave: Encefalite Viral; Hospitalização; Saúde Pública.

\begin{abstract}
Introduction: Viral encephalitis is a condition with high morbidity and mortality rates, and a better understanding of its epidemiology may contribute to the construction of prevention and control strategies. For this reason, this study aimed to draw an epidemiological profile for viral encephalitis in Brazil in 2018 from data on hospitalizations in the Unified Health System (SUS). Methods: Ecological study of spatial analysis. The data studied were hospitalizations for viral encephalitis in SUS in 2018, stratified by federation unit (FU), gender, and age group. The geographical distribution was approached in an exploratory way, whereas gender and age variables were analytically addressed. Results: There were 2075 hospitalizations, with a rate of $0.99 / 10^{5}$ inhabitants. The rates for each FU were represented in a colorimetric map, whereas the rates for each sex and age group were exemplified in a univariate comparative table. Discussion: There was a wide numerical variation in hospitalization rates among the FUs, with Pernambuco being the state with the highest incidence $\left(4.13 / 10^{5}\right.$ inhabitants) and Paraíba with the lowest $\left(0.29 / 10^{5}\right.$ inhabitants). A significant association was found with the risk of hospitalization for viral encephalitis for males and the ages from 1 to 4 years (RR: 3.28) and under one year (RR: 6.02). Conclusion: FU, gender, and age group were important determinants of the hospitalization rate due to viral encephalitis. However, current studies are needed in Brazil and worldwide to better characterize the epidemiology of viral encephalitis.
\end{abstract}

Keywords: Encephalitis, Viral; Hospitalization; Public Health.

1. Instituto Multidisciplinar em Saúde (IMS), Universidade Federal da Bahia (UFBA), Vitória da Conquista (BA), Brasil.

$\triangle$ Instituto Multidisciplinar em Saúde. Rua Hormindo Barros, 58, Quadra 17, Lote 58, Bairro Candeias. CEP: 45.029-094. Vitória da Conquista (BA) Brasil.

elenacairess@gmail.com | Recebido em: 29/12/2019 | Aprovado em: 24/06/2020 


\section{INTRODUÇÃO}

Encefalite corresponde a uma irritação ou inflamação do parênquima cerebral associada à disfunção neurológica clinicamente manifesta ${ }^{1}$. Essa condição pode ser causada por uma gama de agentes infecciosos, sendo a etiologia viral a mais comum. Os agentes virais mais comumente associados são os herpesvírus 1 e 2, arbovírus, enterovírus não pólio, flavivírus e influenza $A^{2,3}$. A frequência destes agentes, no entanto, varia de acordo com a localização geográfica, a estação do ano, o status imunológico do paciente e a mutação viral no transcorrer do tempo ${ }^{3}$. Em muitos casos, pode ser difícil o reconhecimento do agente etiológico, de maneira que a causa provável ou confirmada só é estabelecida em 37 a $70 \%$ dos pacientes ${ }^{4,5}$.

Embora infecções virais sistêmicas pelos agentes etiológicos mais implicados em seu desenvolvimento sejam usuais, a ocorrência da encefalite é incomum. Apesar de ser relativamente rara, trata-se de uma condição clínica que apresenta altas taxas de morbidade e mortalidade, sobremaneira quando há atraso em seu reconhecimento e manejo, o que lhe confere grande relevância epidemiológica ${ }^{6-8}$.

Em sentido estrito, encefalite é um diagnóstico patológico determinado somente a partir de confirmação histológica. Todavia, na prática clínica o diagnóstico é guiado pela história e apresentação clínica, bem como por indícios de inflamação cerebral, como pleocitose no líquido cefalorraquidiano e achados sugestivos na neuroimagem ${ }^{7}$. Muitas doenças mimetizam a encefalite, e por isso, muitas vezes, o seu diagnóstico é dificultado ${ }^{9}$.

A apresentação clínica usual da encefalite compreende febre, cefaleia, alteração do nível de consciência, sinais neurológicos focais e, possivelmente, convulsões ${ }^{10}$. Quando severa, pode estar associada à hipotensão/hipertensão, hepatite, insuficiência renal aguda, insuficiência respiratória e morte devido a sérias complicações sistêmicas $^{11}$. Ademais, pode deixar significativas sequelas, incluindo comprometimento cognitivo e comportamental, distúrbios afetivos e crises epilépticas ${ }^{8}$.

Um melhor entendimento no que concerne à epidemiologia da encefalite pode colaborar para a construção de melhores estratégias de prevenção e controle ${ }^{8}$. Diante disto, e levando em conta que a encefalite é uma condição potencialmente letal e com possíveis sequelas em longo prazo, este estudo se propôs a traçar um perfil epidemiológico para a encefalite viral no Brasil no ano de 2018 a partir dos dados de internações hospitalares no Sistema Único de Saúde (SUS) dela decorrentes, levando em conta sua distribuição geográfica e associação com sexo e faixa etária.

\section{MÉTODOS}

Trata-se de um estudo ecológico de análise espacial, compreendendo todas as unidades federativas (UF) do Brasil. Os dados estudados foram relativos às internações hospitalares por encefalite viral no SUS, por local de residência, em 2018. Tais dados foram coletados no Sistema de Informação Hospitalar (SIH), do Departamento de Informática do Sistema Único de Saúde (DATASUS), que confere dados relativos à morbidade hospitalar do SUS. Para a obtenção desses dados, foi selecionado o conteúdo "Autorizações de Internação Hospitalar aprovadas" referente à encefalite viral, que no sistema abarca os itens A83-A86 do CID10, para os meses de janeiro de 2018 a dezembro de 2018, elencados por local de ocorrência. Para cálculo das taxas, foram utilizadas como dados populacionais as projeções da população brasileira para o ano de 2018, disponíveis no sítio do Instituto Brasileiro de Geografia e Estatística (IBGE), na seção "Projeção da População". Por se tratar de um estudo com dados secundários e agregados, abertos a consulta pública e sem identificação pessoal, não foi necessária avaliação por Comitê de Ética.

Os dados foram estratificados por unidade da federação, sexo e faixa etária (menor que 1 ano, 0 a 4 anos, 5 a 19 anos, 20 a 39 anos, 40 a 59 anos, 60 a 79 anos e 80 anos ou mais). A distribuição geográfica das internações hospitalares por encefalite viral no SUS foi analisada a partir de uma abordagem exploratória. Já as variáveis sexo e faixa etária foram analisadas a partir de uma abordagem analítica.

No que se refere à distribuição geográfica, foram calculadas as taxas de internação por encefalite viral para cada UF, por $10^{5}$ habitantes, as quais foram ajustadas para idade a partir do método direto, utilizando como população padrão a população brasileira. 
Para determinar a associação com sexo e faixa etária, inicialmente foram calculadas as taxas de internação hospitalar por encefalite viral para cada sexo e faixa etária. Na sequência, procedeu-se a comparação univariada a partir das razões de taxas (risco relativo), utilizando um intervalo de confiança (IC) de 95\%.

\section{RESULTADOS}

No período do estudo, foram registradas 2075 internações hospitalares por encefalite viral no SUS em todo o Brasil, e a população brasileira projetada para o período foi de 209.186.802 habitantes. A Tabela 1 apresenta o total de casos, o total de habitantes e a taxa de internações/100.000 habitantes em cada UF. Já a Figura 1 consiste de um mapa colorimétrico que apresenta estas taxas corrigidas por idade, ilustrando a ampla variação geográfica encontrada.

A Tabela 2 apresenta a distribuição da população brasileira em 2018 em relação a sexo e faixa etária. Já a Tabela 3 apresenta o número e a taxa de internações hospitalares no SUS por encefalite viral no período para cada categoria dentro das duas variáveis.

Tabela 1

Taxa de internação hospitalar por encefalite viral no SUS por UF em 2018, não corrigida para a idade

\begin{tabular}{|c|c|c|c|}
\hline Estado & População & No de internações & $\begin{array}{l}\text { Taxa de Internação* } \\
\text { (por } 105 \text { habitantes) }\end{array}$ \\
\hline Pernambuco & 9.534 .634 & 390 & 4,13 \\
\hline Amazonas & 4.124 .033 & 78 & 1,89 \\
\hline Maranhão & 7.043 .339 & 122 & 1,73 \\
\hline Paraná & 11.396 .262 & 168 & 1,47 \\
\hline Rio Grande do Sul & 11.356 .804 & 141 & 1,24 \\
\hline Santa Catarina & 7.090 .682 & 81 & 1,14 \\
\hline Goiás & 6.860 .047 & 71 & 1,04 \\
\hline Mato Grosso & 3.382 .487 & 35 & 1,04 \\
\hline Tocantins & 1.567 .016 & 17 & 1,09 \\
\hline Roraima & 530.879 & 6 & 1,13 \\
\hline Ceará & 9.055 .744 & 80 & 0,88 \\
\hline Acre & 842.290 & 9 & 1,07 \\
\hline Distrito Federal & 3.101 .220 & 24 & 0,77 \\
\hline Mato Grosso do Sul & 2.743 .142 & 22 & 0,80 \\
\hline Alagoas & 3.391 .142 & 25 & 0,74 \\
\hline Minas Gerais & 21.235 .870 & 158 & 0,74 \\
\hline Rondônia & 1.813 .741 & 14 & 0,77 \\
\hline Piauí & 3.224 .536 & 22 & 0,68 \\
\hline São Paulo & 45.429 .330 & 302 & 0,66 \\
\hline Sergipe & 2.309 .961 & 15 & 0,65 \\
\hline Rio de Janeiro & 16.798 .421 & 95 & 0,60 \\
\hline Rio Grande do Norte & 3.538 .218 & 22 & 0,62 \\
\hline Pará & 8.457 .229 & 56 & 0,66 \\
\hline Espírito Santo & 4.058 .079 & 23 & 0,57 \\
\hline Bahia & 15.408 .079 & 84 & 0,55 \\
\hline Amapá & 812.961 & 3 & 0,37 \\
\hline Paraíba & 4.050 .662 & 12 & 0,30 \\
\hline Total & 209.186.802 & 2075 & 0,99 \\
\hline
\end{tabular}

Fonte dos dados: Instituto Brasileiro de Geografia e Estatística (IBGE) e Sistema de Informação Hospitalar (SIH)

*Não corrigida por idade. 


\begin{tabular}{|c|c|c|}
\hline \multicolumn{3}{|c|}{ Legenda } \\
\hline & Taxa & Estado \\
\hline & 4,13 & PE \\
\hline & 1,90 & AM \\
\hline & 1,68 & MA \\
\hline & 1,51 & PR \\
\hline & 1,32 & RS \\
\hline & 1,15 & SC \\
\hline & 1,05 & GO \\
\hline & 1,04 & MT \\
\hline & 0,94 & TO \\
\hline & 0,88 & RR \\
\hline & 0,86 & CE \\
\hline & 0,80 & AC \\
\hline & 0,79 & DF \\
\hline & 0,79 & MS \\
\hline & 0,77 & AL \\
\hline & 0,75 & MG \\
\hline & 0,72 & RO \\
\hline & 0,70 & PI \\
\hline & 0,69 & SP \\
\hline & 0,65 & SE \\
\hline & 0,60 & RJ \\
\hline & 0,60 & RN \\
\hline & 0,59 & PA \\
\hline & 0,58 & ES \\
\hline & 0,54 & BA \\
\hline & 0,30 & AP \\
\hline & 0,29 & PB \\
\hline
\end{tabular}

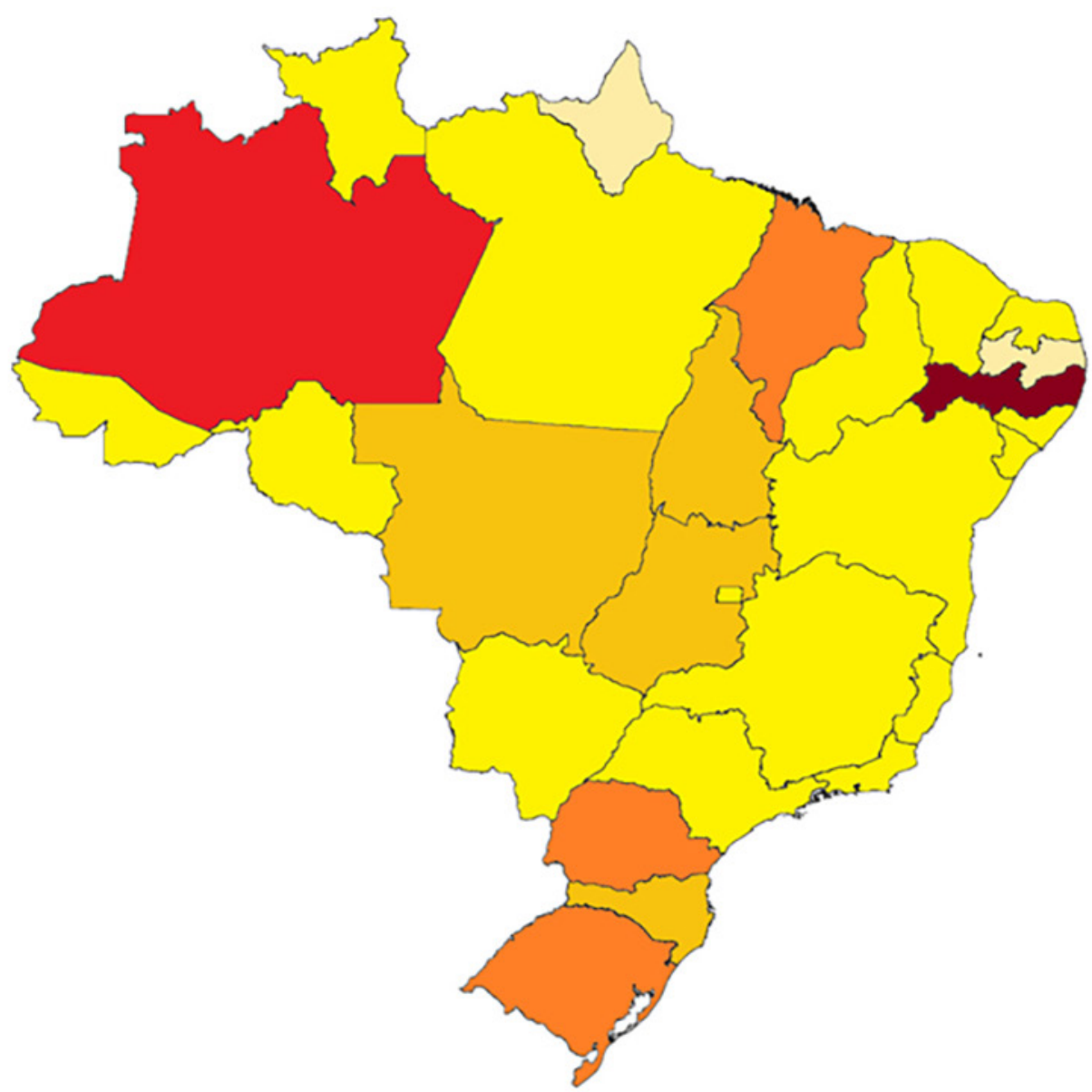

Figura 1: Mapa colorimétrico das taxas de internação hospitalar por encefalite viral no SUS por UF em 2018 (por $10^{5}$ habitantes), corrigidas por idade

Tabela 2

Proporção por sexo e faixa etária da população brasileira em 2018

\begin{tabular}{lcc}
\hline Variável & $\mathbf{N}$ & $\%$ \\
\hline Sexo & 105996973 & 50,7 \\
$\quad$ Feminino & 103189829 & 49,3 \\
$\quad$ Masculino & & 1,8 \\
Faixa etária & 3789567 & 11,1 \\
80 anos ou mais & 23244596 & 24,4 \\
60 a 79 anos & 51128797 & 32,7 \\
40 a 59 anos & 68416676 & 23,1 \\
5 a 39 anos 19 anos & 48424200 & 5,5 \\
1 a 4 anos & 11408482 & 1,3 \\
Menor que 1 ano & 2774484 & \\
\hline
\end{tabular}

Fonte: Instituto Brasileiro de Geografia e Estatística (IBGE) 


\section{Tabela 3}

Comparação univariada da associação entre sexo/faixa etária e internação hospitalar por encefalite viral no SUS em 2018

\begin{tabular}{|c|c|c|c|c|c|}
\hline Variável & No de casos & $\begin{array}{l}\text { Taxa de internação* } \\
\text { (por } 105 \text { habitantes) }\end{array}$ & $\mathbf{R R}$ & IC $(95 \%)$ & $\mathbf{P}$ \\
\hline \multicolumn{6}{|l|}{ Sexo } \\
\hline Feminino & 919 & 0,87 & 1,0 & & \\
\hline Masculino & 1156 & 1,12 & 1,29 & $1,18-1,40$ & $<0,0001$ \\
\hline \multicolumn{6}{|l|}{ Faixa etária } \\
\hline 80 anos ou mais & 32 & 0,84 & 1,0 & & \\
\hline 60 a 79 anos & 225 & 0,97 & 1,15 & $0,79-1,66$ & 0,7 \\
\hline 40 a 59 anos & 417 & 0,82 & 0,97 & $0,67-1,38$ & 0,85 \\
\hline 20 a 39 anos & 421 & 0,62 & 0,72 & $0,51-1,04$ & 0,084 \\
\hline 5 a 19 anos & 523 & 1,08 & 1,28 & $0,90-1,82$ & 0,17 \\
\hline 1 a 4 anos & 316 & 2,77 & 3,28 & $2,28-4,71$ & $<0,0001$ \\
\hline Menor que 1 ano & 141 & 5,08 & 6,02 & $4,10-8,83$ & $<0,0001$ \\
\hline
\end{tabular}

Fonte dos dados: Instituto Brasileiro de Geografia e Estatística (IBGE) e Sistema de Informação Hospitalar (SIH).

\section{DISCUSSÃO}

Em linhas gerais, a epidemiologia da encefalite viral não é bem compreendida em virtude da variação nos critérios diagnósticos e da ocorrência de sub-registro e subestimativa do número de $\operatorname{casos}^{12}$.

A incidência mundial de encefalite viral é desconhecida, e as taxas variam conforme a localização geográfica ${ }^{13}$. Um estudo canadense de base populacional realizado por Dubey et al. $(2018)^{14}$ demonstrou uma incidência de encefalite viral de $1,0 / 100000$ pessoa-anos. O relatório da força tarefa sobre doenças tropicais realizado pela Federação Mundial das Sociedades de Cuidados Médicos Intensivos e Críticos apontou uma incidência anual de $6,34 / 100000^{15}$. Dois estudos realizados a partir de uma base de dados hospitalares estadunidense por George et al. (2014) ${ }^{16}$ e Vora et al. (2013) ${ }^{17}$ encontraram uma taxa de hospitalização anual de aproximadamente $7 / 100000$. Já um estudo que revisou dados hospitalares canadenses encontrou uma taxa de hospitalização de $1,64 / 100000^{18}$. Por fim, um estudo epidemiológico com dados hospitalares italianos conduzido por Barbadoro et al. revelou uma taxa de hospitalização por encefalite viral de $1,05 / 100000^{19}$.

Para o presente estudo, calculou-se uma taxa de internação hospitalar para a encefalite viral no Brasil em 2018 de 0,99/100000 habitantes, valor próximo aos encontrados por Dubey et. al. e Barbadoro et al. em seus estudos supracitados, e substancialmente menor do que os revelados por George et al., Vora et al. e pelo relatório da Federação Mundial das Sociedades de Cuidados Médicos Intensivos e Críticos. Considerando-se que a encefalite viral é uma condição clínica que requer hospitalização ${ }^{20}$, essa taxa apresenta boa correspondência com a incidência documentada dos diagnósticos realizados. Um fator limitante à acurácia do dado, no entanto, é o possível subdiagnóstico e subnotificação relativo à doença.

No que se refere à distribuição geográfica, observou-se ampla variação numérica das taxas de internação, sendo que a razão entre as taxas de Pernambuco e Paraíba (estados com a maior e menor taxa corrigida por faixa etária, respectivamente) foi igual a 14,44. A taxa de internação de Pernambuco foi 4,17 vezes maior do que a brasileira, enquanto a da Paraíba foi 3,47 vezes menor.

Em relação ao gênero, foi constatada uma associação significativa com o risco de internação hospitalar por encefalite viral para o sexo masculino, que apresentou um risco 1,29 vezes superior ao sexo feminino $(p<0,0001)$. Também se verificou associação significativa com a faixa etária, com os indivíduos de 1 a 4 anos e menores do que 1 ano apresentando taxas de internação hospitalar por encefalite viral em 2018 de 5,08/100000 habitantes e 2,77/100000 habitantes, respectivamente, e riscos relativos (em relação à faixa etária adotada como referência para comparação 
univariada) de 6,02 ( $p<0,0001)$ e 3,28, respectivamente. Observou-se, ainda, uma discreta redução na taxa de hospitalização para as faixas de 20 a 39 anos e 40 a 59 anos, a qual, no entanto, não teve significância estatística ( $p=0,084$ e $p=0,85$, respectivamente).

A maior incidência de encefalite viral em homens (RR: 1,2) observada no estudo coincide com o que foi encontrado por Lee et al. em um estudo de base hospitalar prospectivo (RR: 1,4$)$. Os estudos conduzidos por Barbadoro et al. (2012) ${ }^{19}$, Studahl et al. (1998) $)^{21}$ e Khetsuriane, Holman \& Anderson (2002) 22 $^{2}$ também encontraram maior incidência no sexo masculino. Por outro lado, os estudos conduzidos por Kulkarini et al. (2013) ${ }^{18}$, Vora et al. ${ }^{17}$ e Venkatesan et al. (2013) ${ }^{23}$ encontraram maior incidência de encefalite viral em mulheres.

No presente estudo, constatou-se maior taxa de internação por encefalite viral na população pediátrica, com os menores do que 1 ano apresentando risco 6,02 vezes maior ( $p<0,0001)$ em relação à faixa etária adotada como referência, e a faixa etária de 01 a 04 anos apresentando risco 3,28 vezes maior $(p<0,0001)$. O risco relativo para a faixa etária que apresentou maior taxa de internação - menor que 1 ano - foi de 8,26 (IC95\%: 6,82 - 9,99; $p<0,0001)$ em relação à faixa etária que apresentou menor taxa de internação - 20 a 39 anos. É bem estabelecido na literatura que os infantes apresentam maiores taxas de encefalite viral, e a maior incidência na faixa etária específica menor do que 1 ano também foi observada por Koskinemi et al. (1997) ${ }^{24}$, Davison et al. (2003) ${ }^{25}$ e Buhl \& Lindquist (2009) 26 .

Apresentaram-se como principais limitações ao presente estudo a adoção de diferentes critérios e condutas diagnósticas em diferentes serviços hospitalares, bem como a possibilidade de subdiagnóstico e subnotificação da encefalite viral, que pode variar entre as unidades da federação.

\section{CONCLUSÃO}

O presente estudo constatou UF, gênero e faixa etária como determinantes importantes da taxa de internação hospitalar por encefalite viral no Brasil em 2018. As taxas foram substancialmente maiores em Pernambuco do que no restante do território nacional, e o sexo masculino e as faixas etárias menor do que 1 ano e de 01 a 04 anos apresentaram maior risco relativo para internação hospitalar pela doença. Esses achados salientam a importância da realização de estudos epidemiológicos concernentes à encefalite viral, que podem vir a ser uma importante ferramenta de apoio ao raciocínio diagnóstico. Diante disso, cumpre exortar a realização de tais estudos, posto que carecem de estudos atuais no Brasil e no mundo para a melhor caracterização da epidemiologia da encefalite viral.

\section{CONFLITO DE INTERESSES}

Declaro não haver nenhum conflito de interesses.

\section{FONTE DE FINANCIAMENTO}

Declaro que o estudo não recebeu nenhum financiamento.

\section{REFERÊNCIAS}

1. Steiner I, Budka H, Chaudhuri A, Koskiniemi M, Sainio $K$, Salonen $O$, et a. Viral encephalitis: a review of diagnostic methods and guidelines for management. Eur J Neurol I. 2005;12(5):331-43.doi: https://doi. org/10.1111/j.1468-1331.2005.01126.x

2. NUNES Cristina Freitas. Etiologia das encefalites e meningites de líquor claro [doutorado]. 2018. São Paulo: Instituto de Medicina Tropical de São Paul da Universidade de São Paulo; 2018. doi: https://dx.doi. org/10.11606/T.99.2018.tde-27112018-144215

3. Viral encephalitis: a practical review on diagnostic approach and treatment. J Pediatr (Rio J).

4. Beyond viruses: clinical profiles and etiologies associated with encephalitis. Clinical Infectious Diseases. 2006;43(12):1565-1577. doi: https://doi. org/10.1086/509330

5. Simon DW, Da Silva YS, Zuccoli G, Clark RSB. Acute Encephalitis. Critical Care Clinics. 2013;29(2):259-277. doi: https://doi.org/10.1016/j.ccc.2013.01.001

6. Mower K. Early recognition of encephalitis in acute settings. Emergency Nurse. 2017;25(1): 27-31. doi: https://doi.org/10.7748/en.2017.e1651

7. Solomon T, Hart IJ, Beeching NJ. Viral encephalitis: a clinician's guide. Practical neurology. 2007;7(5):288305. doi: http://dx.doi.org/10.1136/jnnp.2007.129098 
8. Granerod J \& Crowcroft NS. (2007) The epidemiology of acute encephalitis. Neuropsychological Rehabilitation: An International Journal. 2007;17(4-5):406-428. doi: https://doi.org/10.1080/09602010600989620

9. Weingarten $L$, Enarson $P$, Klassen $T$. Encephalitis. Pediatric Emergency Care. 2013;29(2):235-244. doi: https://doi.org/10.1016/j.pediatrneurol.2015.03.013

10. Stone MJ, Hawkins CP. A medical overview of encephalitis. Neuropsychological Rehabilitation. 2007;17(4-5):429-449. doi: https://dx.doi.org/10.1080/09602010601069430

11. Bale Jr. JF. Virus and Immune-Mediated Encephalitides: Epidemiology, Diagnosis, Treatment and Prevention. Pediatric Neurology. 2015;53(1):3-12. doi: https://doi. org/10.1016/j.pediatrneurol.2015.03.013

12. Thompson C, Kneen, R, Riordan A, et al. Encephalitis in Children. Arch Dis Child. 2012;97(2):150-161. doi: https://dx.doi.org/10.1136/archdischild-2011-300100

13. Puccioni-Sohler M. Encefalite Viral. In: Joaquim Pereira Brasil Neto; Osvaldo M. Takayanagui. (Org.). Tratado de Neurologia da Academia Brasileira de Neurologia. 1ed. Rio de Janeiro: Elsevier Editora Ltda., 2013, v. 84, p. 742-747.

14. Dubey D, Pittock SJ, Kelly CR, McKeon A, Lopez-Chiriboga AS, Lennon VA, Flanagan E. Autoimmune encephalitis epidemiology and a comparison to infectious encephalitis. Annals of Neurology. 2018;83(1):166-177. doi: https://doi.org/10.1002/ana.25131

15. Silva GS, Richards GA, Baker T, Amin PR, Council of the World Federation of Societies of Intensive and Critical Care Medicine. Encephalitis and myelitis in tropical countries: Report from the Task Force on Tropical Diseases by the World Federation of Societies of Intensive and Critical Care Medicine. Journal of Critical Care. 2017;(42):355-359. doi: https://dx.doi.org/10.1016/j. jcrc. 2017.11.001

16. George BP, Schneider EB, \& Venkatesan A. Encephalitis Hospitalization Rates and Inpatient Mortality in the United States, 2000-2010. PloS one. 2014;9(9):e104169. https://doi.org/10.1371/journal.pone.0104169

17. Vora NM, Holman RC, Mehal JM, Steiner CA, Blanton JD \& Sejvar JJ. Burden of encephalitis-associated hospitalizations in the United States, 1998-2010. Neurology. 2013;82(5):443-51. doi: https://doi.org/10.1212/ WNL.0000000000000086
18. Kulkarini $M$, Lecocq $A$, Artsob $H$, Drebot $M$, Ogden N. Epidemiology and aetiology of encephalitis in Canada, 1994-2008: A case for undiagnosed arboviral agents? Epidemiology and Infection. 2013;141(11):2243-2255. doi: https://doi. org/10.1017/S095026881200252X

19. Barbadoro P, Marigliano A, Ricciardi A, D'errico Mm, Prospero E. Trend of hospital utilization for encephalitis. Epidemiology and Infection. Cambridge University Press. 2012;140(4):753-64. doi: https://doi.org/10.1017/ s0950268811001002

20. Steiner I, Budka H, Chaudhuri A, Koskiniemi M, Sainio K, Salonen O, Kennedy PG. Viral encephalitis: a review of diagnostic methods and guidelines for management. European journal of neurology. 2005;12(5):331-43. doi: https:// dx.doi.org/10.1111/j.1468-1331.2005.01126.x

21. Studahl M, Bergstrom T, Hagberg L. Acute viral encephalitis in adults: A prospective study. Scandinavian Journal of Infectious Diseases. 1998;30:215-220. doi: https:// dx.doi.org/10.1080/00365549850160828

22. Khetsuriani N, Holman RC, Anderson L J. Burden of encephalitis-associated hospitalizations in the United States, 1988-1997. Clinical Infectious Diseases. 2002;35:175-182. doi: https://doi.org/10.1086/341301

23. Venkatesan $A$, Tunkel $A R$, Bloch $K C$, Lauring AS, Sejvar J, Bitnun A, Stahl JP, Mailles A, Drebot M, Rupprecht $\mathrm{CE}$, Yoder J. Case definitions, diagnostic algorithms, and priorities in encephalitis: consensus statement of the international encephalitis consortium. Clinical Infectious Diseases. 2013;57(8):1114-1128. doi: https://doi. org/10.1093/cid/cit458

24. Koskiniemi M, Korppi $M$, Mustonen $K$, Rantala $H$, Muttilainen $M$, Herrgård $E$, Vaheri $A$. Epidemiology of encephalitis in children. A prospective multicentre study. European Journal of Pediatrics. 1997;156(7):541545. doi: https://doi.org/10.1007/s004310050658

25. Davison KL, Crowcroft NS, Ramsay $M E$, et al. Viral encephalitis in England, 1989-1998: what did we miss? Emerging Infect Dis. 2003;9:234-40. doi: https://doi. org/10.3201/eid0902.020218

26. Buhl MR, Lindquist L. Japanese encephalitis in travelers: review of cases and seasonal risk. Journal of travel medicine. 2009;16(3):217-9. doi: https://doi. org $/ 10.1111 / \mathrm{j} .1708-8305.2009 .00333 . x$ 